\title{
Detecting patterns of change in benthic habitats by acoustic remote sensing
}

\author{
A. Rattray ${ }^{1}$, D. Ierodiaconou ${ }^{1, *}$, J. Monk ${ }^{1}$, V. L. Versace $^{2}$, L. J. B. Laurenson ${ }^{1}$ \\ ${ }^{1}$ School of Life and Environmental Sciences, Faculty of Science and Technology, and ${ }^{2}$ University Department of Rural Health, \\ Deakin University, Greater Green Triangle, Warrnambool, Victoria 3280, Australia
}

ABSTRACT: Changes in benthic habitats occur as a result of natural variation or human-induced processes. It is important to understand natural fine-scale inter-annual patterns of change to separate these signals from patterns of long-term change. Describing change from an acoustic remote sensing standpoint has been facilitated by the recent availability of full coverage swath acoustic datasets, but is limited by cost pressures associated with multiple surveys of the same area. We studied the use of landscape transition analysis as a means to differentiate seemingly random patterns of habitat change from systematic signals of habitat transition at a shallow (10 to $50 \mathrm{~m}$ depth) $18 \mathrm{~km}^{2}$ site on the temperate Australian continental shelf in 2006 and 2007. Supervised classifications for each year were accomplished using independently collected highresolution swath acoustic and video reference data. Of the 4 representative biotic classes considered, signals of directional systematic changes occurred between a kelp-dominated class, a sessile invertebrate-dominated class and a mixed class of kelp and sessile invertebrates. We provide a detailed analysis of the components of the traditional change detection cross tabulation matrix, allowing identification of the strongest signals of systematic habitat transitions. Identifying patterns of habitat change is an important first step toward understanding the processes that drive them.

KEY WORDS: Multibeam sonar - Kelp · Video • Monitoring $\cdot$ Habitat mapping

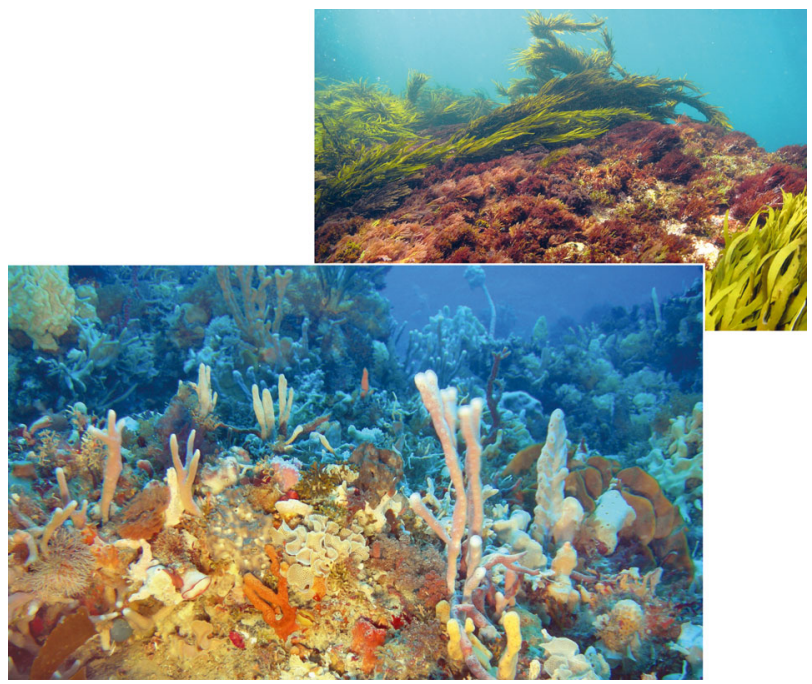

Diverse sessile invertebrate communities typically encountered on deep reefs in Victorian coastal waters, Australia.

Image: D. Ierodiaconou

\section{INTRODUCTION}

Anthropogenic disturbance may lead to fundamental shifts in ecosystem dynamics, expressed as a reduction of biodiversity, loss of production and disruption of ecological services (Worm et al. 2006). Understanding the temporal dynamics of benthic habitats is a key component to their effective management.

The coast of southern Australia is a temperate marine biodiversity hotspot (Wernberg et al. 2011). Highenergy rocky reefs along Australia's southern coastline support 30 to $40 \%$ of the world's species of macroalgae, of which half are considered endemic. 
Invertebrate communities are similarly highly speciose and display significant (>90\%) rates of endemism. Ocean temperatures in southeastern Australia have warmed at an average rate of $0.23^{\circ} \mathrm{C}$ decade $^{-1}$ since the early 1950 s, a rate that is 4 times the global average (Ridgway 2007). Benthic species in this region are deemed to be particularly vulnerable to increases in water temperatures associated with climate change and changes in ocean circulation, because the lack of suitable hard substratum to the south of the Australian continent precludes any poleward migration. Because of the length of the temperate southern coastline $(>3000 \mathrm{~km})$ and the relatively narrow latitudinal band that it occupies (Wernberg et al. 2011), even small changes in the distribution of key habitat-forming species such as kelps have the potential to translate into significant habitat shifts across thousands of square kilometres.

Kelps are foundation species that control communities and ecological processes by modifying the physical environment and resources for other organisms (Wernberg et al. 2010). Deleterious effects of human-induced stressors on kelp habitats, particularly changes associated with increasing ocean temperatures, are likely to have widespread cascading effects across other temperate marine habitats and ecosystems (Johnson et al. 2011). Surface canopies of the giant kelp Macrocystis pyrifera in the southeastern Australian region have been in decline since 1944 (Edyvane 2003), with some areas experiencing as much as $90 \%$ reduction in visible surface canopy. This trend has been related to incursions of warm, nutrient-poor water during strong El Niño-Southern Oscillation events (Johnson et al. 2011) and southward range expansion of a barren-forming urchin species (Ling et al. 2009). Estimates of changes in the distribution of $M$. pyrifera have been derived largely through the use of historical aerial imagery, facilitated by the fact that the species often forms dense canopies at the surface.

Remote sensing of biological habitat boundaries in the shallow sub-littoral using optical sensors is well established. Satellite and airborne multi-spectral, hyperspectral and photographic imagery have been applied to assess distributions of coral reefs (Mumby \& Edwards 2002), seagrass (Phinn et al. 2008) and temperate macroalgal communities (Bekkby et al. 2009). Availability and relative ease of access to timeseries imagery has also facilitated monitoring of change in optically shallow sub-littoral habitats over time (Palandro et al. 2008).

However, most temperate reef habitats are beyond the range of optical sensors due to the attenuation of light in the water column with increasing depth, compounded by factors such as turbidity and wave action at the surface (Kutser et al. 2006).

Concerted efforts are underway to improve capacities for spatial demarcation and management of marine benthic habitats beyond the range of optical sensors. The recent proliferation of full-coverage, high-resolution, acoustic datasets and subsequent development of methods to relate acoustic returns with distinct geological and biological facies of the seafloor (see Brown et al. 2011 for review) have engendered interest in establishing acoustic remote sensing based approaches for continuous monitoring of benthic species (Paul et al. 2011) and communities (Van Rein et al. 2011). In 57 recent case studies, 24 intended habitat mapping to be a part of a monitoring program, and another 24 reported that habitat maps would form the baseline for monitoring future changes (Harris \& Baker 2011). Despite the intent of practitioners to assess temporal variability in marine habitats using acoustic remote sensing methods, there is a notable dearth of studies exploring methods to achieve this end.

A number of studies have described temporal morphological dynamics of the seafloor using serial acoustic bathymetry (e.g. Duffy \& Hughes-Clarke 2005, Smith et al. 2007). Until recently, however, assessments of biological change beyond the range of optical sensors have been based primarily on ground sampling methods that are logistically limited to safe, repeatable diving depths (ca. <20 m) and are confined to small areas due to safety and cost constraints.

We investigated approaches to quantify temporal change in benthic habitats from a spatially explicit seascape-scale perspective using acoustic means. Our objectives were to: (1) quantify change in terms of gains and losses in the extent of habitats at a site on the temperate southeast Australian continental shelf; (2) distinguish between systematic and random patterns of habitat change; and (3) assess the applicability of supervised acoustic remote sensing methods for broad-scale habitat change assessment.

\section{MATERIALS AND METHODS}

\section{Study site}

The study area (Fig. 1) comprised $18 \mathrm{~km}^{2}$ of overlapping multibeam echosounder (MBES) surveys conducted in 2006 and 2007 as part of the Victorian Marine Habitat Mapping Program. The 

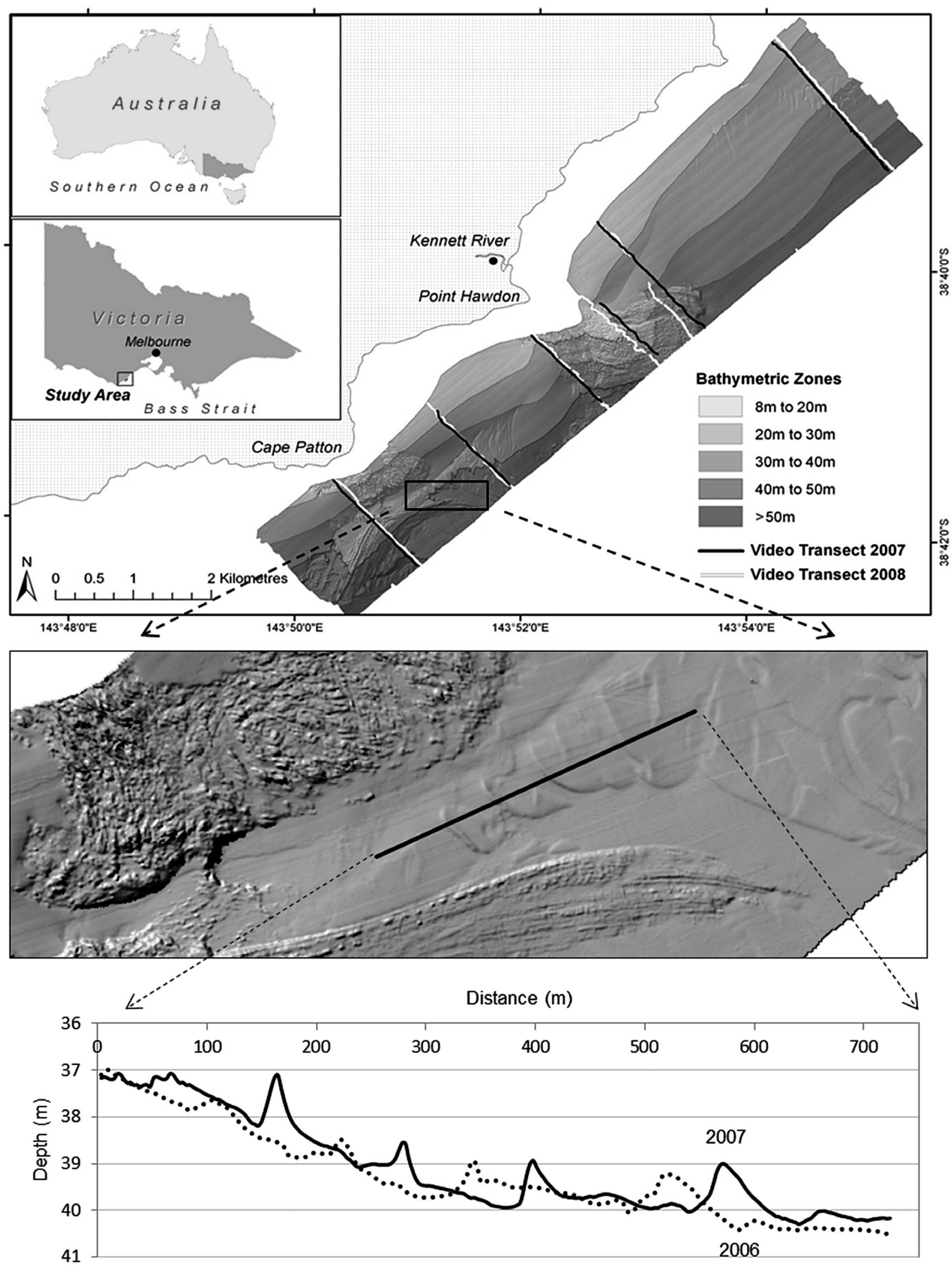

Fig. 1. Study site in Bass Strait, Australia, showing $10 \mathrm{~m}$ bathymetric zones overlaying multibeam bathymetry (survey year 2007). Video transect locations for each year are displayed as black (2006) and white (2007) lines. Time series bathymetric profiles indicate longshore movement of sediments through the site, potentially causing scour on low-profile reef margins 
2006 survey targeted 5 marine national parks and 13 locations of perceived significance within Victorian state waters, resulting in $655 \mathrm{~km}^{2}$ of MBES bathymetry and backscatter intensity data. The 2007 survey resulted in a further $607 \mathrm{~km}^{2}$ of MBES data and was aimed at linking 3 discrete survey sites in the central western sector of the state, to provide continuous coverage between these areas within the state's $3 \mathrm{n}$ mile jurisdiction.

The study area was primarily dominated by morphologically flat sandy sediments, although some areas of sediment starvation were apparent, where underlying pavement was exposed between dune structures. The area has 3 distinct sectors of contiguous reef: 2 highly complex basalt reef systems extend seaward from (1) Point Hawdon $\left(38^{\circ} 40^{\prime} 19^{\prime \prime} \mathrm{S}, 143^{\circ}\right.$ $52^{\prime} 10^{\prime \prime}$ E) and (2) Cape Patton (38 41' 25" S, $143^{\circ} 50^{\prime}$ $27^{\prime \prime} \mathrm{E}$ ) to depths of $40 \mathrm{~m}$, and there is (3) a well-bedded comparatively low profile shore-parallel reef between 35 and $50 \mathrm{~m}$ depth at the area's southwestern margin.

The site is exposed to prevailing southwesterly wind and sea conditions and subject to a maximum tidal range of ca. $2 \mathrm{~m}$. Coastal sediment transport occurs via prevailing west to east alongshore drift conditions. Sediment movement was visually assessed by comparing time-series bathymetric profiles and was evident between the 2 multibeam surveys, particularly in a channel between the 2 reef systems in the southwest of the site (Fig. 1).

\section{Data acquisition and processing}

\section{Acquisition}

Surveys were carried out using a hull-mounted Reson Seabat 8101 echosounder (December 2006 and December 2007) at an operational frequency of $240 \mathrm{kHz}$ and $150^{\circ}$ angular sector coverage. Ping rate was range dependent, from 40 pings $\mathrm{s}^{-1}$ at the shallow margins of the area to 15 pings $\mathrm{s}^{-1}$ at depths approaching $50 \mathrm{~m}$. Positioning was accomplished using a Starfix HP differential Global Positioning System (dGPS $\pm 0.30 \mathrm{~m})$, integrated with a Positioning and Orientation System for Marine Vessels (POS $\mathrm{MV})$ for pitch, roll heave and yaw corrections $\left( \pm 0.02^{\circ}\right.$ accuracy). Data logging, real-time quality control, display, navigation and post-processing were carried out using the Starfix Suite 7.1 (Fugro Survey proprietary software). Prior to commencing the sonar survey, a tide gauge was deployed, with data corrected to Lowest Astronomical Tide. Daily sound velocity profiles were collected to correct for local variations in water column sound velocity (deepest at $51 \mathrm{~m}$ ). Track spacings were designed to provide $50 \%$ overlap between adjacent lines over all depths (i.e. increasing distance between survey tracks with increasing depth) allowing for rejection of data at acute grazing angles.

\section{Processing}

The sounding data were post-processed onboard the vessel to hydrographic standard weighted by International Hydrographic Organization (IHO) Order 1 uncertainty. The XYZ data were used to produce a bathymetric grid at $3 \mathrm{~m}$ horizontal resolution and a range resolution of $\pm 12.5 \mathrm{~mm}$. Raw backscatter values were corrected for transmission loss, the actual area of ensonification on the bathymetric surface, source level, and transmit and receive beam patterns (see Fonseca et al. 2009). Additionally, backscatter was corrected for seafloor bathymetric slope from the MBES bathymetric dataset to normalise the signal to the value at nadir. This resulted in a normalised corrected grid (1 $\mathrm{m}$ resolution) representing relative backscatter intensity (dB) across the study site. In order to standardise 32-bit backscatter intensity images between surveys, they were additionally rescaled to 8-bit images. Full resolution 8-bit backscatter intensity mosaics $(1 \mathrm{~m})$ were resampled to the optimum grid-cell resolution of the bathymetry $(3 \mathrm{~m})$ to facilitate combined processing of both data types. This resolution accounts for most of the spatial error in the co-location of video transect points ( $\pm 3 \mathrm{~m}$ propagated horizontal error at $50 \mathrm{~m}$ depth).

To further characterise local variation within the MBES imagery and to aid in delineating analogous regions of morphology and signal scattering, a suite of secondary products was derived from the bathymetry and backscatter datasets (see Table 1 in Ierodiaconou et al. 2011). These derivatives were selected for their expected influence in the distribution of biological assemblages, as found in previous investigations. They represent variation in seafloor characteristics in terms of exposure to wave energy and benthic currents (aspect, Benthic Position Index: BPI), susceptibility to sediment accumulation (slope, BPI), complexity and surface area of reef structure (complexity, rugosity, maximum curvature) and variations in high and low frequency signal scattering properties of the substratum (Hue-Saturation-Intensity). 


\section{Video reference data}

Within the context of classification based analyses, in situ reference data are used for calibration and validation. The reference data used here were acquired using an acoustically positioned towed video sled collected as soon as was operationally possible after each MBES survey (in both cases within $1 \mathrm{mo}$ ). After consulting all available datasets, 5 shoreperpendicular transects were selected to capture the range of morphological, bathymetric and acoustic scattering variation within the area. Surveys in both years were carried out along the same transects defined using an Omnistar dGPS receiver, although due to differences in localised wind and sea conditions, this did not always translate to exact copositioning of the camera system at the seabed between surveys (Fig. 1). Detailed descriptions of methods used to acquire and classify video imagery are available in Rattray et al. (2009) and Ierodiaconou et al. (2011) and summarised here.

The towed video platform was maintained at $1 \mathrm{~m}$ above the seafloor by a winch operator observing real-time video on board the survey vessel in order to ensure a consistent field of view (approximately $2 \mathrm{~m}^{2}$ ). An Ultra Short BaseLine (USBL) transponder attached to the video unit allowed 3-dimensional positioning of the video unit relative to the vessel's dGPS antenna, which was located directly above the pole mount housing the USBL transceiver. Angular rates of roll, pitch and azimuth $\left( \pm 0.1^{\circ}\right)$ at the dGPS antenna were measured and corrected using a KVH motion sensor.

\section{Classification scheme}

Video frames deemed unsuitable for classification purposes due to sub-optimal visibility caused by turbidity or proximity to the seafloor were rejected. Video frames were classified according to a simplified 4 class schema (adapted from Rattray et al. 2009) describing the major biological and physical components of the site (Table 1). The classification scheme comprised a sediment class (SED) where no epibiota were visible in the video footage, and 3 biological reef classes: a kelp-dominated class (ALGDOM), an invertebrate-dominated class (INVDOM) and a mixed class at the interface of algal and invertebratedominated reef habitats (ALG/INV). The mixed class was included in the classification scheme as it is deemed to represent an important transition in both community composition and physical habitat structure

Table 1. Summary of the 4 category classification scheme employed in supervised classification of the study area for 2006 and 2007. The characteristics for each habitat class are outlined. Associated descriptive statistics were derived from independently collected (between times) multibeam echosounder bathymetry and backscatter (relative 8-bit) products gridded at a resolution of $3 \mathrm{~m}$

\begin{tabular}{|c|c|c|c|c|c|}
\hline \multirow{2}{*}{$\begin{array}{l}\text { Habitat descriptor } \\
\text { Qualitative description of class end-members }\end{array}$} & \multirow[t]{2}{*}{ Statistic } & \multicolumn{2}{|c|}{ Depth (m) } & \multicolumn{2}{|c|}{ Backscatter } \\
\hline & & 2006 & 2007 & 2006 & 2007 \\
\hline \multicolumn{6}{|l|}{ ALGDOM } \\
\hline Dominant canopy-forming macroalgal species: small patches & Max. & 31.6 & 28.7 & 45.7 & 56.2 \\
\hline of the kelp Phyllosphora comosa and occasional Sargassum & Min. & 15.1 & 15.1 & 151.0 & 143.0 \\
\hline and Cystophora spp. in the bathymetric highs giving way to & Mean & 21.3 & 20.1 & 94.5 & 100.6 \\
\hline dense canopies of the common kelp Ecklonia radiata on deeper & $\mathrm{SD}$ & 3.4 & 2.9 & 21.1 & 18.2 \\
\hline reefs with sparse to medium understorey of mixed red algae & Range & 16.5 & 13.6 & 105.3 & 86.8 \\
\hline \multicolumn{6}{|l|}{ ALG/INV } \\
\hline Mix of generally massive and encrusting sponge forms in a & Max. & 31.5 & 31.7 & 80.0 & 99.5 \\
\hline mosaic of patches under a thinning canopy of E. radiata with & Min. & 27.0 & 28.5 & 150.6 & 156.9 \\
\hline \multirow[t]{3}{*}{ mixed red algal understorey } & Mean & 29.3 & 28.5 & 127.4 & 142.1 \\
\hline & SD & 1.1 & 1.8 & 14.8 & 9.5 \\
\hline & Range & 4.5 & 3.2 & 70.6 & 57.4 \\
\hline \multicolumn{6}{|l|}{ INVDOM } \\
\hline Dense sponge-dominated invertebrate communities display- & Max. & 48.1 & 48.0 & 81.5 & 98.1 \\
\hline ing high morphological diversity on high-profile solid reef to & Min. & 27.1 & 23.9 & 186.0 & 217.3 \\
\hline small globular and pedunculate sponges on sand swept & Mean & 36.8 & 34.5 & 153.1 & 161.6 \\
\hline \multirow[t]{2}{*}{ pavement reef and in dune troughs } & $\mathrm{SD}$ & 4.2 & 4.4 & 15.7 & 23.0 \\
\hline & Range & 21.0 & 24.1 & 104.5 & 119.2 \\
\hline \multicolumn{6}{|l|}{ SED } \\
\hline Unconsolidated sandy sediments - inshore fine sandy & Max. & 51.5 & 50.9 & 19.1 & 23.6 \\
\hline sediments with low morphological complexity to & Min. & 14.1 & 14.0 & 209.2 & 229.0 \\
\hline coarse shelly sand in irregular dune formations & Mean & 30.3 & 29.0 & 108.4 & 117.9 \\
\hline \multirow[t]{2}{*}{ offshore, wavelengths to $30 \mathrm{~m}$} & $\mathrm{SD}$ & 9.7 & 10.4 & 40.6 & 51.0 \\
\hline & Range & 37.4 & 36.9 & 190.1 & 205.4 \\
\hline
\end{tabular}


between algal-dominated shallow reefs and deeper invertebrate-dominated reef communities at the site (Rattray et al. 2009). Classified point video data were resampled using a nearest neighbour function and gridded to $3 \mathrm{~m}$ cell size to facilitate integration with co-located physical datasets.

\section{Supervised image classification}

The relationships between MBES derived data products and classified video frames were examined using a supervised QUEST (Loh \& Shih 1997) decision tree (DT) approach, which is useful in applications of remotely sensed data that do not follow a Gaussian frequency distribution (Sesnie et al. 2008, Rattray et al. 2009, Ierodiaconou et al. 2011). The univariate DT classification approach derives hierarchical non-linear relationships within the data by recursively partitioning dataset feature spaces into increasingly homogeneous categories based on a splitting criterion. The particular split threshold of a given variable that produces the largest deviance measure is chosen to recursively partition the dependent data and has the potential to be re-examined and used again as input to the tree structure. A total of 10 subsets of the training data were taken and used to prune resultant trees based on cross validation to an optimum size. This resulted in parsimonious tree models that have less chance of being over-fitted to noise in the training data (Loh \& Shih 1997).

\section{Model validation}

The 2 resulting habitat distribution maps were assessed for accuracy using contingency matrices (Congalton \& Green 2009). The Kappa (к)-statistic used here considers all cells in a contingency matrix, providing a correction for the proportion of chance agreement between the training sites and test data sets. The Kappa-statistic is a standard statistic to evaluate overall classification accuracy, providing a more conservative estimation than simple percent agreement value (Congalton 1991). Other accuracy statistics such as Producer's Accuracy or omission error (indicating how well training set pixels were classified), User's Accuracy or commission error (indicating the probability that a classified pixel actually represents that category in reality), and Overall Accuracy (the total number of correctly classified pixels divided by the total number of reference pixels) were also evaluated.

\section{Change assessment}

\section{Summary of habitat changes}

A $5 \times 5$ majority filter was applied to classified habitat maps from each time series in order to reduce noise and eliminate single pixels in any class while preserving class boundaries. A transition matrix was created for the time series comparison detailing 'from-to' habitat transitions of each class (Pontius et al. 2004, Braimoh 2006). Habitat changes were summarised in terms of swap and net change, and gain and loss, following the methodology of Pontius et al. (2004). Swap is defined as the change in location of a land cover between Time 1 and Time 2, which derives from simultaneous gross gain and gross loss. Net change is the difference in area of land cover between $t_{1}$ and $t_{2}$. Gain refers to the increase, while loss refers to a decrease in area. This allows the identification of patterns of habitat change separately from a given level of persistence in a landscape (Pontius et al. 2004, Ierodiaconou et al. 2005, Alo \& Pontius 2008).

Habitat persistence

Persistence of each habitat in relation to gain, loss and net change were assessed using persistence indices from Braimoh (2006). The gain to persistence ratio was calculated as $g_{\mathrm{p}}=$ gain/persistence, the loss to persistence ratio was calculated as $l_{\mathrm{p}}=$ loss/persistence, and the net change to persistence ratio was calculated as $n_{\mathrm{p}}=g_{\mathrm{p}}-l_{\mathrm{p}}$. Values of $g_{\mathrm{p}}>1$ indicate a gain from other habitat categories, while values of $l_{\mathrm{p}}>1$ indicate a transition to another category.

\section{Random and systematic transitions}

Gains and losses of habitat types over time can be due to random or systematic patterns of habitat change. Pontius et al. (2004) detailed methods to compute expected habitat gains under a random process of gain by distributing observed gains among categories according to their relative proportions at $\mathrm{t}_{1}$. Similarly, expected losses can be calculated by distributing observed losses among categories relative to their proportions at $t_{2 i}$ see Pontius et al. (2004) and Braimoh (2006) for formulae. The relative differences between observed and expected gains and observed and expected losses are then compared to derive a measure of the nature of transitions between habitat categories. 
Large deviations from 0 indicate that systematic inter-class transitions, rather than random transitions, occurred between 2 habitat types (Braimoh 2006). Positive values indicate the inclination of one class to gain or lose from another, while negative values indicate a disinclination of one class to gain or lose. Expected gains and losses are calculated independently of one another with a total of 48 possible gain/loss signals between classes using a 4 class schema. It is possible for systematic gain or loss of one habitat category from another category to occur independently of any reciprocal systematic gain or loss. Therefore, reciprocal systematic gain/loss relationships between 2 classes are needed in order provide conclusive evidence of a dominant signal of habitat transition (Alo \& Pontius 2008).

\section{RESULTS}

\section{Temporal habitat classifications}

Independently derived spatial models representing distribution of the 4 representative habitat classes at the site were developed using an automated DT approach. Distribution of benthic habitats displayed similar patterns for each temporal classification
(Fig. 2) with the Ecklonia radiata-dominated kelp class (ALGDOM) occupying areas of contiguous reef at shallower locations, changing to a narrow transitional band of mixed kelp and sponges (ALG/INV) with increasing depth. Sponge-dominated invertebrate communities (INVDOM) occupied deeper hard substrata and also heterogeneous reef/sand complexes in areas of low morphological complexity associated with transitions from reef to unconsolidated sediments.

Overall classification accuracy was estimated to be 92.5 and $91.9 \%$, respectively, for the 2006 and 2007 classifications, while the Kappa coefficient of agreement was estimated at 0.83 for both classifications (95\% confidence intervals for $\kappa$ for the 2006 and 2007 classifications are $0.80-0.86$ and $0.79-0.85$, respectively; Table 2). Between-class confusion was found to exhibit strong similarities for both classification attempts with producer's accuracy of all classes other than ALG/INV displaying $>85 \%$ agreement with the reference data.

\section{Summary of habitat transitions}

A pattern of overall persistence is evident with $>90 \%$ of the study area remaining static between

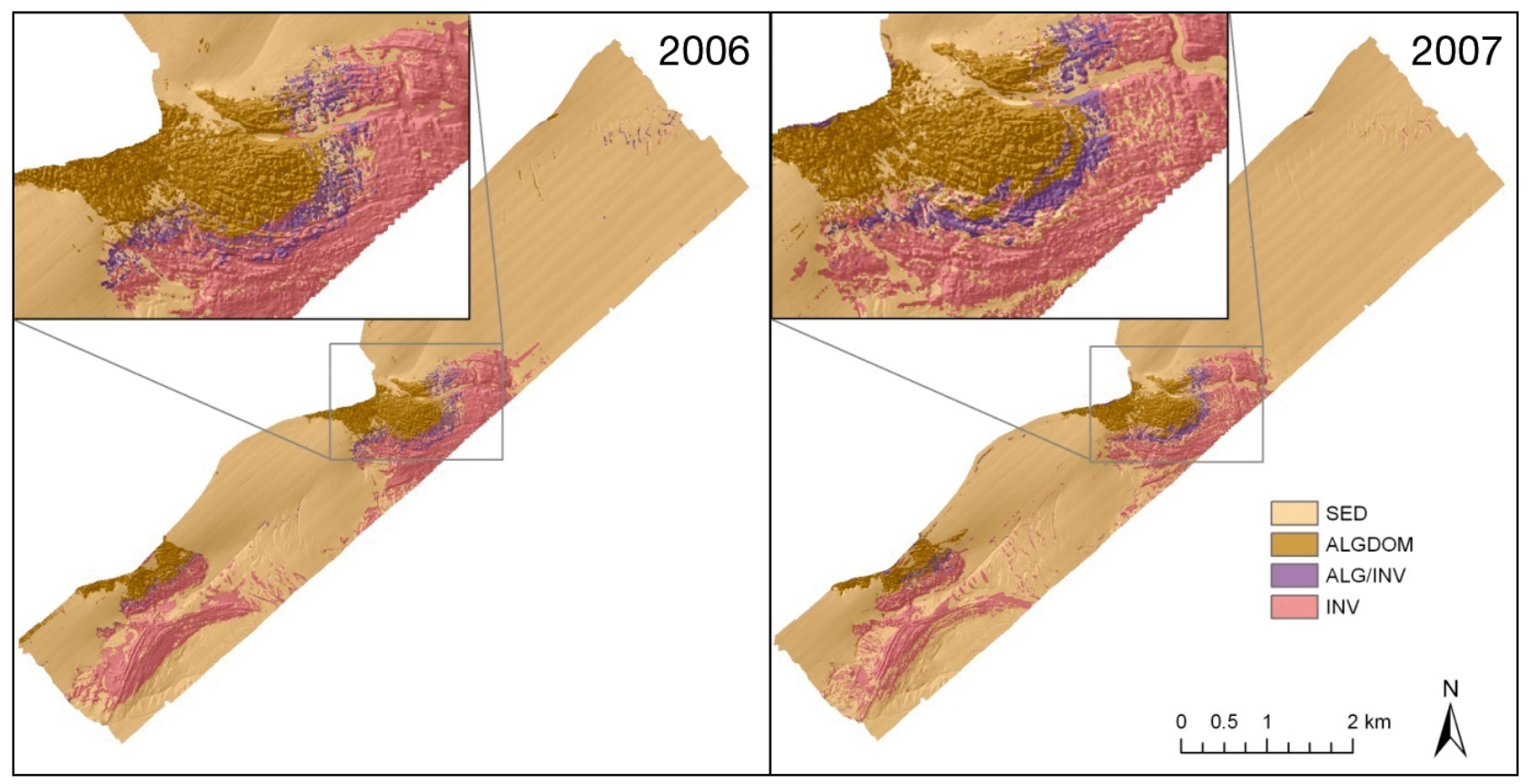

Fig. 2. Supervised classification of the 4 dominant benthic community types in the study area. Habitat classifications were derived from independent swath acoustics (multibeam echosounder, MBES) and towed video surveys using an automated decision tree approach. Habitat classes indicated in the maps are: SED: unconsolidated sandy sediments with no visible epibiota; ALGDOM: kelp-dominated reef; ALG/INV: kelp canopy interspersed with sessile invertebrate communities; INV: reef dominated by sessile invertebrate communities 
Table 2. Confusion matrices for the classified images. Each column corresponds to the ground reference pixels used for accuracy assessment for a single class. The values in a column indicate the number of those ground observation pixels classified into each class, while the values on the main diagonal (italicised) indicate agreement between ground reference points and classified maps. See Table 1 for habitat classifications

\begin{tabular}{|c|c|c|c|c|c|c|c|c|}
\hline Year & Class & SED & ALGDOM & ALG/INV & INVDOM & Total & $\begin{array}{c}\text { Producer } \\
\text { accuracy (\%) }\end{array}$ & $\begin{array}{c}\text { User } \\
\text { accuracy }(\%)\end{array}$ \\
\hline 2006 & $\begin{array}{l}\text { SED } \\
\text { ALGDOM } \\
\text { ALG/INV } \\
\text { INVDOM } \\
\text { Total }\end{array}$ & $\begin{array}{c}1020 \\
11 \\
6 \\
31 \\
1068\end{array}$ & $\begin{array}{c}1 \\
111 \\
2 \\
1 \\
115\end{array}$ & $\begin{array}{c}12 \\
2 \\
24 \\
5 \\
43\end{array}$ & $\begin{array}{c}37 \\
- \\
3 \\
219 \\
259\end{array}$ & $\begin{array}{c}1070 \\
124 \\
35 \\
256 \\
1485\end{array}$ & $\begin{array}{l}96 \\
97 \\
56 \\
85\end{array}$ & $\begin{array}{l}95 \\
89 \\
69 \\
86\end{array}$ \\
\hline 2007 & $\begin{array}{l}\text { SED } \\
\text { ALGDOM } \\
\text { ALG/INV } \\
\text { INVDOM } \\
\text { Total }\end{array}$ & $\begin{array}{c}1070 \\
11 \\
4 \\
52 \\
1137\end{array}$ & $\begin{array}{c}8 \\
116 \\
4 \\
- \\
128\end{array}$ & $\begin{array}{c}1 \\
5 \\
21 \\
7 \\
34\end{array}$ & $\begin{array}{c}36 \\
3 \\
- \\
277 \\
316\end{array}$ & $\begin{array}{c}1115 \\
135 \\
29 \\
336 \\
1615\end{array}$ & $\begin{array}{l}94 \\
91 \\
62 \\
88\end{array}$ & $\begin{array}{l}96 \\
86 \\
72 \\
82\end{array}$ \\
\hline
\end{tabular}

the 2006 and 2007 classifications (Fig. 3), largely driven by the unconsolidated sediment (SED) class (Table 3). Around $78 \%$ of the study area that was classified as unconsolidated sediments in the 2006 classification remained unchanged in 2007. Of the biological classes, INVDOM experienced the highest persistence at $8 \%$ and ALG/INV the lowest at $0.39 \%$ of the study area.

Habitat changes were summarised in terms of swap and net change, and gain and loss (Table 4). SED experienced the greatest gain $(5.5 \%)$, while INVDOM had the greatest loss (4.6\%) (Fig. 3). All classes experienced a net (quantity) loss in percent-

Table 3. Basic change transition matrix (\% of study area). The major diagonal of the matrix (italicised) represents persistence (no change) of classes between years while other values represent 'from-to' changes between habitat categories. See Table 1 for habitat classifications

\begin{tabular}{|c|c|c|c|c|c|}
\hline \multirow{2}{*}{2006 survey } & \multicolumn{5}{|c|}{2007 survey } \\
\hline & SED & ALGDOM & ALG/INV & INVDOM & Total 2006 \\
\hline SED & 78.39 & 0.39 & 0.17 & 2.18 & 81.13 \\
\hline ALGDOM & 0.78 & 3.74 & 0.39 & 0.17 & 5.08 \\
\hline ALG/INV & 0.39 & 0.11 & 0.39 & 0.50 & 1.40 \\
\hline INVDOM & 4.36 & 0.00 & 0.22 & 7.82 & 12.40 \\
\hline Total 2007 & 83.92 & 4.24 & 1.17 & 10.66 & 100.00 \\
\hline
\end{tabular}

age cover between the 2 years, except for SED, which experienced a net gain of $2.8 \%$.

The difference between total change and net change is the amount of swapping or location change. Of the total change over all classes, $71 \%$ is classed as swap, i.e. losses in a given class are replaced by gains from another class. Proportionally, the ALG/INV class experienced the greatest swap-type change, with $87 \%$ of total change attributed to location change and only $13 \%$ attributed to change in quantity (net change).

\section{Persistence of habitats}

Gain $\left(g_{\mathrm{p}}\right)$ and loss $\left(l_{\mathrm{p}}\right)$ to persistence ratios (Table 4) were used to assess the tendency of habitat classes to transition, with ratios exceeding 1 indicating that a habitat category is more likely to gain or lose to other categories than to persist between classifications (Braimoh 2006). The only class to exceed this threshold in terms of either gains or losses was ALG/INV with a $g_{\mathrm{p}}$ ratio of 2.0 and $l_{\mathrm{p}}$ ratio of 2.57 , i.e. it has both a higher tendency to lose and to gain from other classes than to persist, with a high proportion of swapping change and low net change.

Table 4. Changes in habitat classifications expressed as percentage of the study area $\left(18.3 \mathrm{~km}^{2}\right)$. Gains and losses in habitat types between years are attributed to swapping (location) change and net (quantity) change. $g_{\mathrm{p}}=$ gain $/$ persistence, $l_{\mathrm{p}}=$ loss/persistence, $n_{\mathrm{p}}=$ net change/persistence. See Table 1 for habitat classifications

\begin{tabular}{|lrrrrrrrrrr|}
\hline & Total 2006 & Total 2007 & Gain & Loss & Total change & Swap (location) & Net (quantity) & $g_{\mathrm{p}}$ & $l_{\mathrm{p}}$ & $n_{\mathrm{p}}$ \\
\hline SED & 81.13 & 83.92 & 5.53 & 2.74 & 8.26 & 5.47 & 2.79 & 0.07 & 0.03 & 0.04 \\
ALGDOM & 5.08 & 4.24 & 0.50 & 1.34 & 1.84 & 1.01 & -0.84 & 0.13 & 0.36 & -0.22 \\
ALG/INV & 1.40 & 1.17 & 0.78 & 1.01 & 1.79 & 1.56 & -0.22 & 2.0 & 2.57 & -0.57 \\
INVDOM & 12.40 & 10.66 & 2.85 & 4.58 & 7.43 & 5.70 & -1.73 & 0.36 & 0.59 & -0.22 \\
Total & 100.00 & 100.00 & 9.66 & 9.66 & 19.32 & 13.74 & 5.58 & & \\
\hline
\end{tabular}




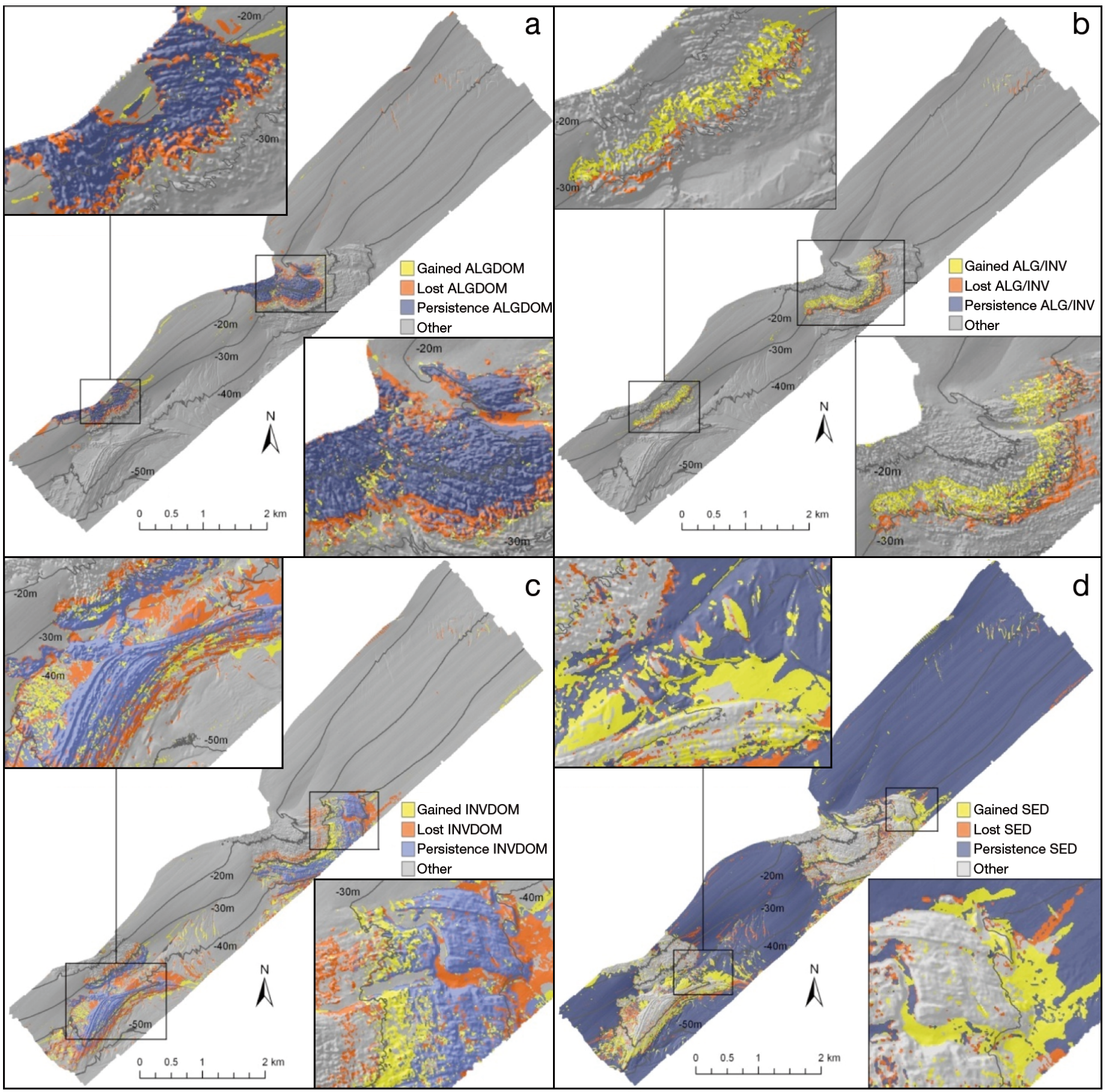

Fig. 3. Gains, losses and persistence between the years 2006 and 2007 for classes (a) ALGDOM, (b) ALG/INV, (c) INVDOM and (d) SED (see Table 1). Persistence (blue) indicates no change in habitat attributions. Gains and losses (yellow and red, respectively) indicate where habitat types have changed in distribution: Grey not modelled

\section{Systematic and random transitions}

The expected gains under a random process of gain are presented in Table 5. Expected gains under a random process of gain were generated by distributing the gain of each class across other classes rela- tive to their proportions in 2006 assuming that the gain of each class and the proportion of each class in 2007 are fixed (see Pontius et al. 2004). Values closer to 0 indicate a random or expected process of gain, while numbers farther away from 0 signify a more systematic process of gain (Table 5). In a similar man- 
Table 5. Inter-category gains and losses between years, showing those expected under a random process of gain (percentage of study area) and relative differences between observed inter-category transitions and expected gains. See Table 1 for habitat classifications

\begin{tabular}{|lcccc|}
\hline \multirow{2}{*}{2006 survey } & \multicolumn{4}{c|}{ 2007 survey } \\
\cline { 2 - 5 } & SED & ALGDOM & ALG/INV & INVDOM \\
\hline Gains & & & & \\
Random & & & & \\
SED & 78.39 & 0.43 & 0.64 & 2.64 \\
ALGDOM & 1.49 & 3.74 & 0.04 & 0.17 \\
ALG/INV & 0.41 & 0.01 & 0.39 & 0.05 \\
INVDOM & 3.63 & 0.07 & 0.10 & 7.82 \\
Difference & & & & \\
SED & 0.00 & -0.09 & -0.74 & -0.17 \\
ALGDOM & -0.47 & 0.00 & 8.70 & 0.01 \\
ALG/INV & -0.04 & 14.11 & 0.00 & 10.08 \\
INVDOM & 0.20 & -1.00 & 1.27 & 0.00 \\
& & & & \\
Losses & & & & \\
Random & & & & \\
SED & 78.39 & 0.72 & 0.20 & 1.81 \\
ALGDOM & 1.17 & 3.74 & 0.02 & 0.15 \\
ALG/INV & 0.85 & 0.05 & 0.39 & 0.11 \\
INVDOM & 4.30 & 0.19 & 0.05 & 7.82 \\
Difference & & & & \\
SED & 0.00 & -0.46 & -0.16 & 0.20 \\
ALGDOM & -0.33 & 0.00 & 22.82 & 0.12 \\
ALG/INV & -0.54 & 1.34 & 0.00 & 3.69 \\
INVDOM & 0.01 & -1.00 & 3.16 & 0.00 \\
\hline
\end{tabular}

ner, values close to 0 indicate that losses are occurring randomly while values farther away from 0 represent increasingly systematic type change.

Systematic transitions were observed between the ALGDOM, ALG/INV and INVDOM classes. The ALG/INV class was systematically replaced by the INVDOM class. The ALGDOM class was systematically replaced by the ALG/INV class. Conversely, the ALG/INV class was also systematically replaced by the ALGDOM class, although these changes were weaker and patchily distributed (Fig. 4).

\section{DISCUSSION}

Monitoring the spatial dynamics of sublittoral benthic habitats beyond the reach of optical sensors and diver surveys is important for marine conservation and planning. This study has demonstrated the applicability of supervised acoustic methods to achieve this end by summarising change in terms of gains and losses, swap (location) change and absolute (net) change of 4 habitats. Further analysis allowed differentiation of systematic from random patterns of

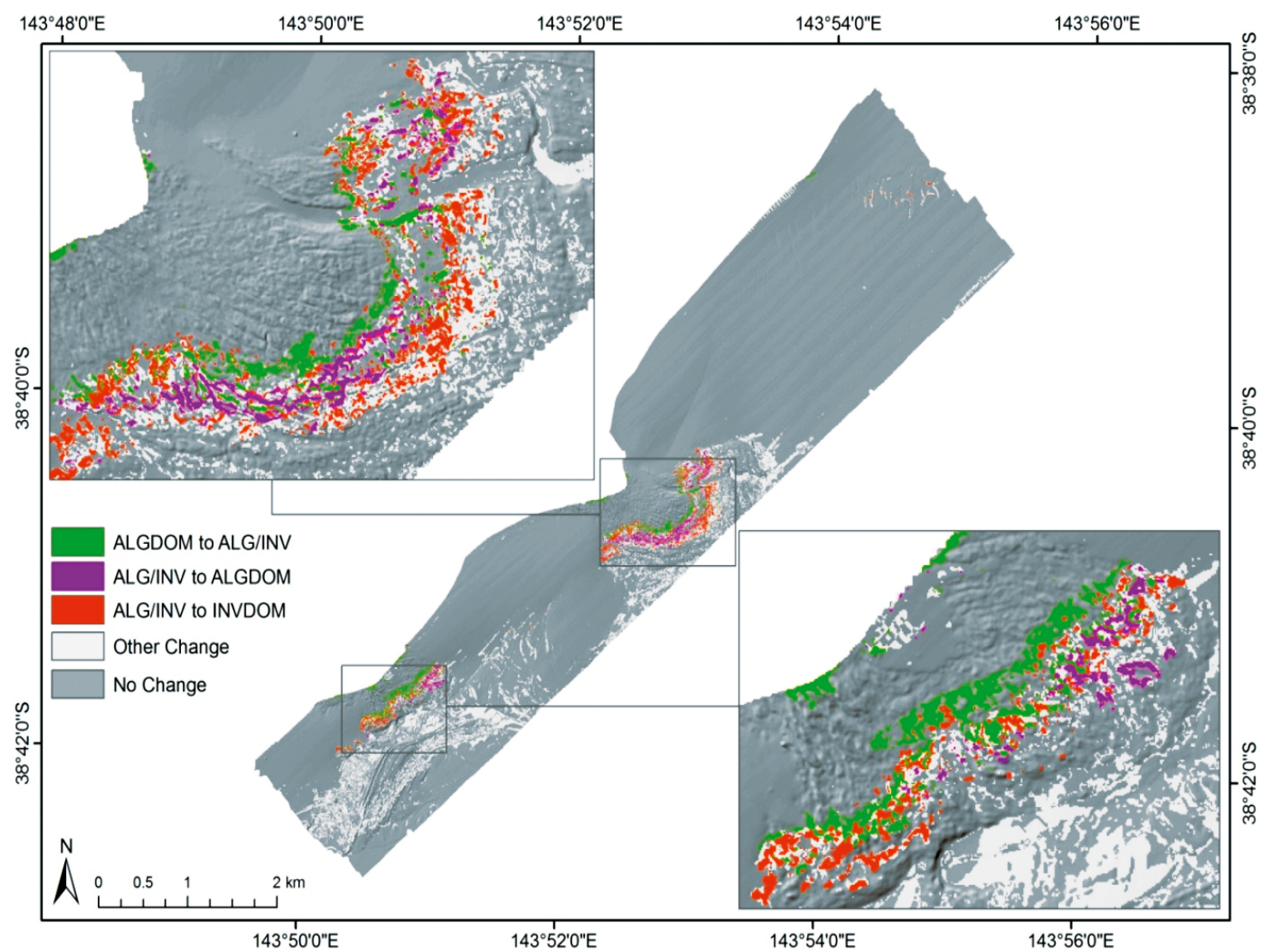

Fig. 4. Spatial distribution of reciprocal systematic gain/loss habitat transitions occurring at the study site between the years 2006 and 2007. Concurrent incidences of systematic gains and losses between classes show habitat transitions from ALGDOM to ALG/INV (shown in green), ALG/INV to INVDOM (shown in red) and ALG/INV to ALGDOM (shown in purple). See Table 1 for habitat classes 
change between classes, based on ratios between observed and expected change.

\section{Habitat transitions}

Quantifying change based solely on areal extents would indicate that the most important transitions were occurring between the sediment-dominated (SED) and the invertebrate-dominated (INVDOM) classes, which comprise $>85 \%$ of the site. Even relatively small changes in these classes have the potential to obscure transitions in smaller classes (Alo \& Pontius 2008).

The largest change component was found to be random, with $\sim 68 \%$ of the total change $(\sim 6.5 \%$ of the study area) between SED and INVDOM, mostly where reef margins meet unconsolidated sediments in areas of low morphological complexity (Fig. 3). This may be a result of scouring processes caused by sediment movement along reef fringes, but may also reflect the inability of the classification approach to distinguish between bare sand and sparsely populated sponge habitat in the flat and non-morphologically complex reef-sand interface due to similar acoustic response patterns. The latter interpretation is borne out by overlap between these 2 classes evident in both single date error matrices (Table 2). An amended classification scheme where prolific invertebrate-dominated habitats evident on higher complexity reefs are differentiated from sparse invertebrate communities at reef margins may aid in resolving ambiguity between these classes.

A dynamic relationship between biological classes was observed in this study. Concurrent incidences of systematic gains and losses between classes show a clear transition from ALGDOM to ALG/INV and ALG/INV to INVDOM in a positive depth shift of the transition zone between algal-dominated and invertebrate-dominated habitats. Ecklonia radiata beds are known to exhibit high variability in biomass over short (seasonal and annual) time scales. At similar latitudes, Wernberg \& Goldberg (2008) recorded seasonal variation of $\sim 400 \%$ in standing E. radiata biomass between spring senescence and summer peaks over a 2 yr bi-monthly sampling regime, observing a 2 mo difference in timing of peak biomass between summers. Variation in biomass was related to short-term fluctuation in environmental variables such as water temperature, day length, seasonal quantum light dose and wave height. Systematic habitat transitions observed in this study show patterns consistent with inter-annual variation of canopy density resulting in retraction of kelp cover at the deeper end of its range and subsequent replacement by adjacent habitats.

\section{Accuracy of change detection}

Central to ecologically meaningful change detection is the accuracy of the single date classified images. Quantitative accuracy assessment of single date classifications is important for understanding developed change detection results and also in applying those results for decision making. While single date accuracy assessment of classified images has been well discussed in the literature, methods for assessing accuracy of change detection results are less well explored (Foody 2010). As with single date classifications, change detection error can be categorised by errors associated with spatial (location) and classification (thematic) error (Congalton \& Green 2009). Spatial error in this case has been largely mitigated by the use of dGPS and accurate co-registration of both serial acoustic layers, and ground reference data with acoustic layers using a USBL positioning system. Classification error is more difficult to control and can arise from inconsistently classified reference data, repeatability of the classification process, radiometric differences between serial acoustic datasets, and acoustic similarity of different habitat classes.

An accepted method of providing a general measure of change detection validation is to multiply overall classification accuracies for each single date classification (Serra et al. 2003, Coppin et al. 2004). Applying this method to the current study yields a change detection accuracy of $86 \%(0.93 \times 0.92 \times 100)$, although this measure fails to account for the bias contributed by larger, better defined classes (e.g. SED) to overall classification accuracy. A more conservative error term may be derived by multiplying the 2-date Kappa coefficient of agreement terms which are independent of bias due to class size and provide change detection accuracy of $69 \%(0.83 \times 0.83 \times 100$; Prenzel \& Treitz 2006). A number of approaches to establishing generalised confidence measures for change detection have been proposed. An extension of the single date error matrix for assessment of change detection accuracy was outlined by Congalton \& Green (2009) but requires representative sampling of each possible 'from-to' change class. Pontius \& Lippitt (2006) proposed methods to assess the sensitivity of 2 error matrices in order to determine levels of change above classification error. 


\section{Limitations and outlooks}

Issues inherent in controlling geometric and radiometric distortion between serial acoustic surveys are inextricably linked to the quality of subsequent applications of the data for detecting change. Disparities between time series acoustic datasets may arise as a result of sea conditions at the time of acquisition (Hughes-Clarke 2003), changeability in onboard acquisition parameters (Fonseca \& Mayer 2007) and speed and direction of survey (McGonigle et al. 2010). Backscatter intensity values for each habitat class showed considerable variation between surveys (Table 1). Use of a post-classification approach mitigates this issue by comparing independently derived habitat distribution models (Coppin et al. 2004). However, this raises concerns for future studies, especially those relying on direct comparison of properties of the acoustic return, e.g. algebraic or image differencing approaches (Singh 1989, Coppin et al. 2004). Calibration of time series backscatter remains an issue that needs to be addressed if these data are to be used effectively for conducting change analysis.

The ability to quantify short-term seasonal changes in distribution of kelp-dominated habitats using an acoustic remote sensing approach holds promise for longer-term monitoring efforts, particularly in view of the geographic range and importance to overall ecosystem functioning associated with these species (Wernberg et al. 2011). The dynamic nature of the habitats investigated underscores the requirement to collect contemporary reference data in order to properly represent habitat distribution at a given point in time. To adequately define the extents of temporally variable habitats, further time series data that reflect the variability of controlling environmental drivers are required (Coppin et al. 2004). Consequently, these results should be interpreted within the context of the temporal scale within which they have been measured and the taxonomic resolution of the classification scheme which has been employed. It is, however, important to understand variation over small spatio-temporal scales in order to assess potential future patterns of directional change (Habeeb et al. 2007).

\section{CONCLUSIONS}

In this assessment of change in patterns of habitat distribution between 2 discrete classifications, no assumptions regarding habitat condition or potential drivers of habitat change can be made. The study does identify areas of the seafloor susceptible to change and quantifies the significance of intercategory transitions within the constraints of the timeseries analysed and the classification scheme employed. In describing patterns of variation between broadly defined biological communities at the seafloor in a spatially explicit manner, a better understanding of the temporal dynamics of these communities can be obtained.

Acknowledgements. This work was supported by National Heritage Trust/Caring for our Country and Parks Victoria as part of the Victorian Marine Habitat Mapping Project. We thank the crew of the Australian Maritime College vessel 'Bluefin' and Fugro Survey for their contribution to the collection of MBES data. Spatial analyses were undertaken at Deakin University, Warrnambool, Victoria, GIS Laboratory facility.

\section{LITERATURE CITED}

Alo CA, Pontius RG (2008) Identifying systematic land-cover transitions using remote sensing and GIS: the fate of forests inside and outside protected areas of southwestern Ghana. Environ Plann B Plann Des 35:280-295

Bekkby T, Rinde E, Erikstad L, Bakkestuen V (2009) Spatial predictive distribution modelling of the kelp species Laminaria hyperborea. ICES J Mar Sci 66:2106-2115

Braimoh AK (2006) Random and systematic land-cover transitions in northern Ghana. Agric Ecosyst Environ 113: 254-263

Brown CJ, Smith SJ, Lawton P, Anderson JT (2011) Benthic habitat mapping: a review of progress towards improved understanding of the spatial ecology of the seafloor using acoustic techniques. Estuar Coast Shelf Sci 92:502-520

Congalton RG (1991) A review of assessing the accuracy of classifications of remotely sensed data. Remote Sens Environ 37:35-46

Congalton RG, Green K (2009) Assessing the accuracy of remotely sensed data. CRC Press, Boca Raton, FL

- Coppin P, Jonckheere I, Nackaerts K, Muys B, Lambin E (2004) Digital change detection methods in ecosystem monitoring: a review. Int J Remote Sens 25:1565-1596

Duffy GP, Hughes-Clarke JE (2005) Application of spatial cross correlation to detection of migration of submarine sand dunes. J Geophys Res 110, F4. doi:10.1029/2004JF 000192

Edyvane K (2003) Conservation, monitoring and recovery of threatened giant kelp (Macrocystis pyrifera) beds in Tasmania - final report. Department of Primary Industries, Water and Environment, Hobart

> Fonseca L, Mayer L (2007) Remote estimation of surficial seafloor properties through the application Angular Range Analysis to multibeam sonar data. Mar Geophys Res 28:119-126

> Fonseca L, Brown C, Calder B, Mayer L, Rzhanov Y (2009) Angular range analysis of acoustic themes from Stanton Banks Ireland: a link between visual interpretation and multibeam echosounder angular signatures. Appl Acoust 70:1298-1304 
Foody GM (2010) Assessing the accuracy of land cover change with imperfect ground reference data. Remote Sens Environ 114:2271-2285

Habeeb RL, Johnson CR, Wotherspoon S, Mumby PJ (2007) Optimal scales to observe habitat dynamics: a coral reef example. Ecol Appl 17:641-647

Harris PT, Baker EK (2011) GeoHab Atlas of seafloor geomorphic features and benthic habitats-synthesis and lessons learned. In: Harris PT, Baker EK (eds) Seafloor geomorphology as benthic habitat: GeoHab Atlas of seafloor geomorphic features and benthic habitats. Elsevier, Amsterdam, p 871-888

Hughes-Clarke JE (2003) Dynamic motion residuals in swath sonar data: ironing out the creases. Int Hydrogr Rev 4:15-46

Ierodiaconou D, Laurenson L, Leblanc M, Stagnitti F, Duff G, Salzman S, Versace V (2005) The consequences of land use change on nutrient exports: a regional scale assessment in south-west Victoria, Australia. J Environ Manag 74:305-316

Ierodiaconou D, Monk J, Rattray A, Laurenson L, Versace VL (2011) Comparison of automated classification techniques for predicting benthic biological communities using hydroacoustics and video observations. Cont Shelf Res 31:S28-S38

Johnson CR, Banks SC, Barrett NS, Cazassus F and others (2011) Climate change cascades: shifts in oceanography, species' ranges and subtidal marine community dynamics in eastern Tasmania. J Exp Mar Biol Ecol 400:17-32

Kutser T, Vahtmäe E, Martin G (2006) Assessing suitability of multispectral satellites for mapping benthic macroalgal cover in turbid coastal waters by means of model simulations. Estuar Coast Shelf Sci 67:521-529

Ling SD, Johnson CR, Ridgway K, Hobday AJ, Haddon M (2009) Climate-driven range extension of a sea urchin: inferring future trends by analysis of recent population dynamics. Glob Change Biol 15:719-731

Loh WY, Shih YS (1997) Split selection methods for classification trees. Statist $\operatorname{Sin} 7: 815-840$

McGonigle C, Brown CJ, Quinn R (2010) Insonification orientation and its relevance for image-based classification of multibeam backscatter. ICES J Mar Sci 67:1010-1023

> Mumby PJ, Edwards AJ (2002) Mapping marine environments with IKONOS imagery: enhanced spatial resolution can deliver greater thematic accuracy. Remote Sens Environ 82:248-257

Palandro DA, Andréfouët S, Hu C, Hallock P and others (2008) Quantification of two decades of shallow-water coral reef habitat decline in the Florida Keys National Marine Sanctuary using Landsat data (1984-2002). Remote Sens Environ 112:3388-3399

Paul M, Lefebvre A, Manca E, Amos CL (2011) An acoustic method for the remote measurement of seagrass metrics. Estuar Coast Shelf Sci 93:68-79

Editorial responsibility: Matthias Seaman, Oldendorf/Luhe, Germany
Phinn S, Roelfsema C, Dekker A, Brando V, Anstee J (2008) Mapping seagrass species, cover and biomass in shallow waters: an assessment of satellite multi-spectral and airborne hyper-spectral imaging systems in Moreton Bay (Australia). Remote Sens Environ 112:3413-3425

Pontius RG, Lippitt CD (2006) Can error explain map differences over time? Cartogr Geogr Inf Sci 33:159-171

Pontius RG, Shusas E, McEachern M (2004) Detecting important categorical land changes while accounting for persistence. Agric Ecosyst Environ 101:251-268

Prenzel BG, Treitz P (2006) Spectral and spatial filtering for enhanced thematic change analysis of remotely sensed data. Int J Remote Sens 27:835-854

Rattray A, Ierodiaconou D, Laurenson L, Burq S, Reston M (2009) Hydro-acoustic remote sensing of benthic biological communities on the shallow South East Australian continental shelf. Estuar Coast Shelf Sci 84:237-245

Ridgway KR (2007) Long-term trend and decadal variability of the southward penetration of the East Australian Current. Geophys Res Lett 34:L13613, doi:10.1029/2007GL 030393

- Serra P, Pons X, Saurí D (2003) Post-classification change detection with data from different sensors: some accuracy considerations. Int J Remote Sens 24:3311-3340

> Sesnie SE, Gessler PE, Finegan B, Thessler S (2008) Integrating Landsat TM and SRTM-DEM derived variables with decision trees for habitat classification and change detection in complex Neotropical environments. Remote Sens Environ 112:2145-2159

Singh A (1989) Digital change detection techniques using remotely-sensed data. Int J Remote Sens 10:989-1003

Smith DP, Kvitek R, Iampietro PJ, Wong KD (2007) Twentynine months of geomorphic change in upper Monterey Canyon (2002-2005). Mar Geol 236:79-94

> Van Rein H, Brown CJ, Quinn R, Breen J, Schoeman D (2011) An evaluation of acoustic seabed classification techniques for marine biotope monitoring over broadscales $\left(>1 \mathrm{~km}^{2}\right)$ and meso-scales $\left(10 \mathrm{~m}^{2}-1 \mathrm{~km}^{2}\right)$. Estuar Coast Shelf Sci 93:336-349

- Wernberg T, Goldberg N (2008) Short-term temporal dynamics of algal species in a subtidal kelp bed in relation to changes in environmental conditions and canopy biomass. Estuar Coast Shelf Sci 76:265-272

Wernberg T, Thomsen MS, Tuya F, Kendrick GA, Staehr PA, Toohey BD (2010) Decreasing resilience of kelp beds along a latitudinal temperature gradient: potential implications for a warmer future. Ecol Lett 13:685-694

- Wernberg T, Russell BD, Moore PJ, Ling SD and others (2011) Impacts of climate change in a global hotspot for temperate marine biodiversity and ocean warming. J Exp Mar Biol Ecol 400:7-16

Worm B, Barbier EB, Beaumont N, Duffy JE and others (2006) Impacts of biodiversity loss on ocean ecosystem services. Science 314:787-790

Submitted: July 30, 2012; Accepted: January 14, 2013

Proofs received from author(s): February 20, 2013 